test and the Maximum Step Length test among individuals with the 3 ACE genotypes. I/D genotype individuals stepped faster than $\mathrm{I} / \mathrm{I}$ individuals, and farther than $\mathrm{D} / \mathrm{D}$ individuals $(\mathrm{P}<0.05)$. The ACE gene insertion/deletion polymorphism appears to be associated with deficits in stepping performance in older adults. As poor stepping performance increases risk for falls in older adults, specific ACE genotypes may be associated with increased risk for falls. Knowledge of an individual's ACE genotype may provide added information in evaluating risk for falls in older adults.

\section{PROMOTING ADL INDEPENDENCE IN VULNERABLE ELDERLY: SIX-MONTH FOLLOW-UP OF A PILOT COMPARATIVE TRIAL}

C. $\mathrm{Liu}^{1,3}$, D. Clark",3,4, H. Xü ${ }^{2,3,6}$, N.R. Keith", ${ }^{2,3,5}, 1$. Indiana University School of Health and Rehabilitation Sciences, Indianapolis, Indiana, 2. Regenstrief Institute, Inc., Indianapolis, Indiana, 3. Indiana University Center for Aging Research, Indianapolis, Indiana, 4. Indiana University School of Medicine, Indianapolis, Indiana, 5. Indiana University School of Physical Education and Tourism Management, Indianapolis, Indiana, 6. Indiana University School of Public Health, Indianapolis, Indiana

Muscle strength is essential but insufficient to reduce ADL disability in older adults. A parallel-group randomized controlled trial was conducted to compare whether adding functional and task-oriented training to resistance exercise would generate a greater improvement on ADL performance relative to resistance exercise alone. Fifty-two older adults who showed muscle weakness, lived a sedentary life style, and had ADL difficulty were recruited from local subsidized housing properties. They received 10 weeks of resistance exercise or the 3-Step Workout for Life, which included practicing functional movements and ADL tasks at home in addition to resistance exercise. The Box and Blocks test, Timed Up and Go, and Assessment of Motor and Process Skills were used to measure physical function and ADL performance. At sixmonth follow-up, all three outcomes in the 3-Step Workout for Life group were not different from the baseline while the resistance exercise only group showed a significant decline (mean change in the Box and Blocks $=-4.05, p=0.02$; mean change in the Timed Up and Go $=1.84, p=0.01$; mean change in the Assessment of Motor and Process Skills $=-0.25$, $p=0.01$ ). More importantly, the 3-Step Workout for Life group showed a greater improvement in ADL performance when compared to the resistance exercise only group (group mean difference $=0.37, p<0.01$ ). Adding functional, taskoriented training to resistance exercise may help retain physical function and delay the decline of ADL performance after six months of detraining in vulnerable older adults.

\section{SESSION 540 (POSTER)}

\section{ECONOMICS OF AGING, RETIREMENT, PENSIONS, AND FINANCIAL HEALTH}

\section{EXPERIENCES OF RETIREMENT LIFE AMONG RETIREES UNDER PENSION SCHEMES COVERAGE IN KENYA}

S.M. Mwangi, L. Maina, Sociology, Kenyatta University, Nairobi, Nairobi, Kenya
In Kenya, the number of retirees exiting the laborforce with terminal retirement benefits has been on the rise. Retirement benefits are paid in four different modes, as total lumpsum, or partial lumpsum, or monthly pension, or annuities. Although studies have been conducted to examine the income security related to these modes of payment, the experiences of the retirees receiving particularly total lumpsum benefits have not been systematically documented. Thus, the objectives of the study were: to explain the primary characteristics of the Kenyan retirees; document the experiences of retirees receiving total lumpsum benefits; and recommend ways of dealing with these experiences and challenges. A sample comprising of 978 persons aged 55 years and older were recruited from 9 regions of Kenya. Data was collected using a survey questionnaire and focus group discussions. Majority of them were males, rural residents and married and received pension benefits from among the four types of schemes in Kenya: National Social Security Fund, civil service pension, occupational schemes and voluntary pension schemes. Findings indicate that negative experiences (e.g., mismanaging pensions, business failure, and unplanned lending) outweighed positive experiences (e.g., starting and running successful business, building a house). The study recommends that: retirees be encouraged to annuitize their pension savings in case other sources of retirement income may fail; raise the minimum pension amount to dissuade pensioners from investing their retirement savings; conducting business skills training for those exiting the workforce prior to retirement; and encourage prior retirement planning to avoid income pitfalls in retirement.

\section{HOMEOWNERSHIP, SOCIAL INSURANCE, AND OLD-AGE SECURITY IN THE UNITED STATES AND EUROPE}

S. Mudrazija, B.A. Butrica, Urban Institute, Washington, District of Columbia

Government policies often encourage homeownership as an effective way of building assets and a de facto selfinsurance mechanism for old-age security. In the wake of the Great Recession, however, the homeownership rate in the United States has been declining. It may not rebound to its pre-recession peak in the foreseeable future, and it could decline even further. This project compares the United States and 10 European countries to understand the role of homeownership in retirement security, vis-à-vis public and private pensions, and savings. Using panel data from the Health and Retirement Study and the Survey of Health, Ageing, and Retirement in Europe, it explores trends in homeownership among older adults in different countries, both before and following the Great Recession, and examines how the link between homeownership and old-age financial security differs across these countries. The results show that homeownership rate in the United States $(64 \%)$ is lower than in Southern European countries, and similar or higher compared to Northern and continental European countries. However, older persons in Southern Europe are much less likely than older Americans to tap into housing equity to support their standard of living in retirement. Unlike the United States, European countries have generally not experienced a substantial change in homeownership rates during and following the recent recession, regardless of the difference in 
the severity of the economic crisis across countries. A notable exception is population of lower socioeconomic status. The study concludes with a critical comparison of homeownership-related policies in the United States and Europe.

\section{WOMEN'S BASIC FIRST PILLAR PENSIONS IN EUROPE: WHAT FACTORS IMPACT THE AMOUNT?} S. Bould ${ }^{1,2}$, C. Krekula ${ }^{3}$, C. Gavray ${ }^{4}$, I. Crespi ${ }^{5}$, R. Eleta-De Filippis $^{6}$, N. Nikolaev ${ }^{7}, 1$. Gerontology Institute, University of Massachusetts Boston, Somerville, Massachusetts, 2. University of Delaware, Newark, Delaware, 3. Karlstad University, Karlstads, Sweden, 4. University of Liege, Liege, Belgium, 5. University of Macerata, Macerata, Italy, 6. University of Le Havre, Le Havre, France, 7. alivia Technology, Woburn, Massachusetts

In all 5 of the countries studied, Germany, Sweden, Belgium, France and Italy, women live longer than men and risk having a lower amount of basic pension. This research examines the variables of age, work experience, marital status, educational level, and number of children as predictors of pension amount for women. Unlike men, marital status has a significant impact on pensions; widows have a higher basic pension amount than married women; never married and divorced women do better than married women in Germany, France and Belgium.

This research uses the SHARE data from Wave 5 to establish the basic pension amount. This pension consists of the state managed retirement pension plus old age pensions. These sources provide the principal income for the majority of retirees in these countries as the wage and salary related private occupational pension has limited impact on post retirement income for this cohort. The sample consists of all women over 65 who do not receive any work related income and report a pension amount for the last year of more than 1000 euro.

Initial results indicate that level of education is a significant predictor of pension amount in all countries studied. The women's education is a factor independent of her work experience and probably reflects her marriage prospects. Years of work experience is a significant predictor of pension amount for all countries except Belgium while the number of children is significant only in Germany. Final results will compare equations for women with those for men.

\section{GENDER IN NEO-LIBERAL RETIREMENT INCOME SYSTEMS: COMPARING THE U.S., UK, AND SINGAPORE}

D.A. Street ${ }^{1}$, D. Price ${ }^{2,3}, 1$. Department of Sociology, SUNY at Buffalo, Buffalo, New York, 2. The University of Manchester, Manchester, United Kingdom, 3. Manchester Institute for Collaborative Research on Ageing, Manchester, United Kingdom

A substantial literature highlights how reliance on private sector sources for later life finances systematically disadvantages women. Critics of the neo-liberal policy turn argue that this is because public responsibilities have increasingly been privatized. We critically assess this claim in respect of pensions using a comparative analytic approach to document retirement income systems in the US, UK and Singapore, three liberal countries often regarded as among the vanguard for private arrangements for income. Our conclusions are derived from critical analysis of national policies and secondary analysis of official statistics. We find that, contrary to prevailing assumptions, Singapore (often referred to as the world's most marketized country) has multiple inbuilt state protections that minimize both risks and gender gaps in later life provision for citizens, and has many of the characteristics of protective state systems. However, in Singapore, the most disadvantaged workers, often migrant women, are neither included in national accounts nor considered as potential recipients of income in later life, thus heavily skewing the results. Such low-paid workers are included in data for the other two countries. The US seems to occupy the middle ground among the three countries. Both US and UK rely heavily on a mixed economy of retirement income; however, the greater state support for public pensions in the US Social Security system leads to categorizing the UK as the country where older women, and older people in general, seem most at risk of poor outcomes in old age.

\section{FINANCIAL LITERACY AND THE ECONOMIC EXPERIENCES OF OLDER ABORIGINAL ADULTS IN CANADA}

L. McDonald, E. Relyea, R.M. Mirza, J. Hsieh, K. Mercer, B. MacDonald, C. Aliman, J. Fujioka, Institute for Life Course and Aging, University of Toronto, Toronto, Ontario, Canada

Lifelong socio-economic development disparity between Indigenous Peoples and the general population across Australia, New Zealand, the United States, and Canada is a significant risk factor for marginalization in later years (Brascoupé, Weatherdon, \& Tremblay, 2013). A scoping review on international financial literacy programs conducted prior to this study indicated the need to address financial knowledge gaps in Indigenous populations, specifically focusing on financial literacy across the lifespan. The findings of this review informed this mixed methods research study, drawing on results from a consensus meeting $(n=15)$, survey $(\mathrm{n}=50)$, and focus group data $(\mathrm{n}=25)$ to better understand the financial realities of Canadian elderly Aboriginals who live on and off reserves. The results of the study indicate that the financial capabilities of older Aboriginals are not well understood and that tailored money management initiatives must consider the needs of Aboriginal older adults with lower income. Strategies to improve financial literacy are also complicated by the implications of status, tax-exemptions, gendered income disparities, and band laws. The knowledge gained from this study led to the development of financial literacy resources that address the following issues: navigating financial resources and benefits, saving and education for grandchildren, legal and tax issues, and band issues. The findings from this study are applicable beyond a Canadian context to demonstrate the complexity of financial issues faced by the growing elderly Indigenous communities, and the need for diverse international financial literacy programs to include cultural elements of knowledge translation, cultural relevancy and cultural safety.

\section{GOAL-SETTING TYPOLOGIES EVIDENT AMONG COMMUNITY-DWELLING AUSTRALIAN RETIREES}

D. Dudley, K. O'Loughlin, V. Loh, The University of Sydney, Lidcombe, New South Wales, Australia 